\title{
ANALISIS STRATEGI PEMASARAN TANDAN BUAH SEGAR (TBS) PERKEBUNAN RAKYAT MELALUI KOPERASI (STUDI KASUS KOPERASI TANI BINA MADANI DI KECAMATAN RANTAU KABUPATEN ACEH TAMIANG)
}

\author{
(Analysis Marketing Strategy Of Fresh Fruit Bunches (FFB) Smallholders Through \\ Cooperation (Case Study Of Tani Bina Madani Cooperatvie At Rantau District In Aceh \\ Tamiang Regency))
}

\author{
Mozan Yunaz Putra ${ }^{1}$, Zakiah $^{1}$, Fajri $^{1 *}$ \\ ${ }^{1}$ Program Studi Agribisnis, Fakultas Pertanian, Universitas Syiah Kuala
}

\begin{abstract}
Abstrak. Subsektor perkebunan merupakan salah satu subsektor pertanian yang menyumbangkan devisa negara tertinggi di Indonesia. Di Kecamatan Rantau dan Seruway di Kabupaten Aceh Tamiang sendiri mempunyai potensi alam, khususnya tanah dan iklim yang sangat sesuai untuk usaha perkebunan tanaman kelapa sawit. Kecamatan ini sudah terdapat koperasi yang bergerak di bidang perkebunan yaitu Koperasi Tani Bina Madani. Namun masih ada masalah yang dihadapi koperasi seperti masih sedikitnya ketersediaan TBS dari petani untuk dibawa ke PKS dan buruknya kualitas TBS sehingga masih sering terjadi penolakan dari PKS. Penelitian ini bertujuan untuk mengetahui faktor-faktor internal dan eksternal yang mempengaruhi pemasaran agroindustri, serta untuk mengetahui strategi pengembangan yang menjadi alternatif pada Koperasi Tani Bina Madani. Penelitian ini dilakukan di Desa Suka Rakyat Kecamatan Rantau Kabupaten Aceh Tamiang dengan Koperasi Tani Bina Madani dan seluruh anggota didalamnya sebagai objek penelitiannya. Metode yang dilakukan dalam penelitian ini adalah metode analisis SWOT. Hasil analisis data mengenai posisi perusahaan dengan menggunakan analisis SWOT menunjukkan bahwa strategi pemasaran yang cocok diterapkan pada Koperasi Tani Bina Madani adalah dengan menggunakan strategi SO (Strength Opportunities). Strategi SO dilakukan dengan memanfaatkan kekuatan perusahaan guna menangkap peluang pasar yang tinggi yaitu dengan menguatkan kerjasama dengan pihak PKS dengan mengusahakan kebijakan yang menguntungkan Koperasi.
\end{abstract}

Kata kunci: TBS, SWOT, koperasi, strategi pemasaran.

\begin{abstract}
Plantation is one of many agricultural subsector that contributed in giving the country a lots of foreing exchanges in Indonsia. At Rantau and Seruway Districts in Aceh Tamiang Regency has the potential of nature, in particular the soil and the climate is very suitable for palm oil crops plantation business. This regency already had a cooperative that engaged in plantation sectors named Koperasi Tani Madani. The problems that they faced such cooperatives still lack availability of Oil Palm Fresh Fruit Bunches (FFB) from farmers to the Oil Palm Mill (OPM) bad quality of the FFB so it still often happens that the rejection of the OPM. This research aims to know the internal and external factors of the agro-industries marketing, as well as to know the alternative of development strategy on Farm Cooperative Bina Madani. This research was conducted at Suka Rakyat village Rantau district in Aceh Tamiang Regency with the farmers Cooperative Bina Madani and whole member as the object of the research. This research used SWOT analysis method. The results of the analysis are about the position of companies using SWOT analysis shows that a suitable marketing strategies applied to the Farmers Cooperative Bina Madani is to use strategy SO (Strength Opportunities). The SO strategy is done by using the power of the company to capture high market opportunities with strengthened the cooperation with the OPM with the pursuit of policies that benefit for the cooperative.
\end{abstract}

Keywords: FFB, SWOT, cooperatvie, market strategy.

\section{PENDAHULUAN}

Beberapa dari hasil perkebunan yang menjadi komoditas ekspor antara lain: karet, kelapa sawit, teh, kopi, dan tembakau. Sebagian besar tanamanperkebunan tersebut merupakan usaha 
perkebunan rakyat,sedangkan sisanya diusahakan olehperkebunan besar, baik milik pemerintah maupun milik swasta. Perkebunan rakyat menguasai $81 \%$ dari luas areal perkebunan yang ada di Indonesia, dengan melibatkan sekitar $11.810 .600 \mathrm{KK}$ petani pekebun, dan dengan produksi mencapai 60\% dari seluruh produksi perkebunan (Wahyu, 2012). Di Kecamatan Rantau dan Seruway di Kabupaten Aceh Tamiang sendiri mempunyai potensi alam, khususnya tanah dan iklim yang sangat sesuai untuk usaha perkebunan tanaman kelapa sawit. Berdasarkan Aceh Tamiang Dalam Angka (2015), luas Kecamatan Rantau ada 5.171 Hektar, dan Kecamatan Seruway ada 18.849 Hektar. Dengan beberapa keunggulan yang dimiliki koperasi serta juga peluang yang baik dari lokasi serta citra yang baik dari pihak PT. Mopoli Raya maka koperasi harus menentukan arah strategi pemasaran mereka untuk dapat memaksimalkan semua keunggulan dan peluang itu namun tetap harus memperkecil kerugian yang disebabkan oleh kelemahan mereka agar dapat berkembang dengan baik.

Tujuan dari penelitian ini untuk mengetahui strategi pemasaran yang tepat untuk menentukan strategi pemasaran yang efektif untuk mengembangkan Koperasi Tani Bina Madani.

\section{METODE PENELITIAN}

Penelitian dilakukan di Kecamatan Rantau Kabupaten Aceh Tamiang. Penentuan lokasi pada Kecamatan Rantau ini didasari karena kecamatan ini merupakan salah satu daerah sentra produksi kelapa sawit dan juga di kecamatan ini sudah terbentunya koperasi oleh masyarakat yang menjadi satu-satunya koperasi yang bergerak di bidang pemasaran hasil perkebunan petani di sekitarnya.

Objek dari penelitian ini adalah Koperasi Tani Bina Madani di Kecamatan Rantau Kabupaten Aceh Tamiang dan seluruh petani anggota dari Koperasi tersebut. Ruang lingkup penelitian ini adalah pemasaran, dan kemitraan koperasi dengan PT. Mopoli Raya selaku perusahaan yang mengelola Pabrik Kelapa Sawit (PKS).

Berdasarkan bentuk data yang akan digunakan dalam penelitian ini adalah data kualitatif dan data kuantitatif. Teknik pengumpulan data dilakukan dengan cara data primer dan data sekunder. Data primer didapatkan dengan cara melakukan pengisisan kuisioner, wawancara, observasi, dan juga dokumentasi secara langsung di lokasi penelitian dan data sekunderr didapat dari literature-literatur terkait. Data awal yang dikumpulkan melalui kuisioner dalam penelitian kuantitatif data dalam penelitian ini harus diubah menjadi angka-angka yaitu dengan penyekoran. Skala pengukuran yang digunakan adalah skala Likert. Jawaban setiap instrumen yang menggunakan skala Likert mempunyai gradasi dari yang sangat positif sampai sangat negatif, dapat berupa kata-kata antara lain: Sangat Tinggi, Setuju, Tinggi, Sedang, Rendah dan Sangat Rendah atau Sangat Baik, Baik, Cukup, Tidak Baik dan Sangat Tidak Baik.

Adapun metode yang akan digunakan dalam penelitian ini adalah menggunakan metode analisis faktor internal dan eksternal untuk menentukan titik yang akan dimasukan pada diagram kartesius. Tahapan itu sendiri mulai dari penetuan Bobot setiap butir pertanyaan kuisioner yang ada, lalu menentukan Bobot Item nya, selanjutnya dilakukan pemberian Rating pada masing-masing butir kuisioner dan nantinya didapatkan hasil akhir yaitu Bobot item $\mathrm{x}$ Rating yang dimana menjadi patokan dalam menentukan posisi koperasi dalam diagram kartesius.

Selanjutnya dilakukan analisa SWOT yang merupakan identifikasi berbagai faktor secara sistematis untuk merumuskan strategi perusahaan. Analisa ini didasarkan pada logika yang dapat memaksimalkan kekuatan (Strenggths) dan peluang (Opportunities), namun secara bersamaan dapat meminimalkan kelemahan (Weaknesses) dan ancaman (Threats). Proses pengambilan keputusan strategis selalu berkaitan dengan pengembangan misi, tujuan, strategi, 
dan kebijakan perusahaan. Dengan demikian perencana strategis (strategicplanner) harus menganalisa faktor-faktor strategis perusahaan (kekuatan, kelemahan, peluang dan ancaman) dalam kondisi yang ada saat ini. (Nurmianto, 2004).

\section{HASIL DAN PEMBAHASAN}

Koperasi Tani Bina Madani didirikan pada tahun 2007 oleh masyarakat sekitar setelah diadakannya mufakat dari beberapa kelompok masyarakat Desa Suka Rakyat dan desa sekitarnya di kawasan Kecamatan Rantau Aceh Tamiang. Koperasi ini juga didasari oleh kondisi wilayah sekitar yang didominasi bidang perkebunan akan tetapi petani sekitar masih mengalami kesulitan baik dalam melakukan kegiatan berkebun maupun dalam memasarkan hasil dari kebun yang ada.

Koperasi Tani Bina Madani sendiri awalnya bergerak dibidang simpan pinjam sama seperti koperasi pada umumnya. Namun sejak awal tahun 2017 kegiatan simpan pinjam di koperasi ini dihentikan karena banyaknya jumlah petani yang meminjam di koperasi namun kesulitan dalam melunasi pinjamannya tersebut. Saat ini koperasi hanya bergerak dibidang pemasaran yaitu memasarkan TBS dari petani sekitar ke Pabrik Kelapa Sawit (PKS) yang ada di sekitar wilayah koperasi. Kegiatan ini sendiri dimulai sejak Tahun 2015 dan saat ini sudah berhasil menjadi Koperasi pertama yang menjadi pemasok TBS untuk PKS PT. Mopoli Raya.

\section{Visi dan Misi Koperasi Tani Bina Madani}

a. Visi Koperasi Tani Bina Madani dalam menjalankan kegiatannya adalah sebagai berikut: "Meningkatkan ekonomi masyarakat sekitar di bidang perkebunan".

b. Misi Koperasi Tani Bina Madani dalam mencapai visi tersebut ialah sebagai berikut: "Menghimpun petani sekitar untuk dapat membuat wadah dari hasil pertanian sekitar".

Data dari Koperasi Tani Bina Madani yang telah dikumpulkan dan dilakukan analisis pada faktor internal dan eksternal kemudian digunakan untuk menentukan faktor strategis perusahaan untuk analisis SWOT. Faktor internal dan eksternal pelaksanaan pada Koperasi Tani Bina Madani sebagai berikut:

a. Kekuatan

1. Pengaruh lokasi koperasi dalam proses memasarkan TBS yang dekat dengan PKS.

2. Kualitas tenaga kerja yang ada di koperasi yang kompeten.

3. Peran koperasi untuk petani di sekitarnya yang sudah berkontribusi untuk mensejahterakan masyarakat sekitar.

4. Sumber permodalan untuk koperasi yang baik dengan adanya kemitraan dari berbagai sumber untuk pemodalan.

b. Kelemahan

1. Keterbatasan ketersediaan TBS dari petani yang masih rendahnya pengetahuan petani dalam proses perawatan.

2. Rendahnya kualitas TBS yang ditawarkan ke PKS karena proses pemanenannya yang masih belum tepat serta juga kualitas bibit yang buruk oleh petani.

3. Keterbatasan jumlah petani yang bergabung dengan koperasi karena masih banyak petani yang terikat dengan agen pemasok yang sudah bekerjasama dengan petani sejak lama..

4. Keterbatasan jumlah karyawan koperasi karena koperasi mengutamakan tenaga kerja yang bersungguh-sungguh dalam menjalankan koperasi untuk mensejahterakan masyarakat.

c. Peluang

Analisis Strategi Pemasaran Tandan Buah Segar (TBS) Perkebunan Rakyat Melalui Koperasi 
1. Kemampuan menangkap pangsa pasar yang potensial yaitu menjadikkan PKS PT. Mopoli Raya sebagai target pasar utamanya.

2. Jalinan kerjasama koperasi dengan PKS yang sudah baik walaupun hanya sebagai pemasok pihak ketiga untuk kegiatan produksi PKS PT. Mopoli Raya.

3. Citra koperasi dimata PKS berlangsung baik dengan koperasi sudah terbiasa mennjadi penghubung masyarakat dengan PT. Mopoli Raya.

4. Tingkat daya beli PKS merupakan peluang baik dimana PKS memiliki kapasitas produksi yang tinggi sehingga memerlukan pasokan TBS yang besar.

5. Permintaan pasar terhadap produk TBS koperasi sudah tinggi dimana sudah mulai banya petani yang memutuskan untuk bergabung menjual hasil panennya kepada koperasi.

d. Ancaman

1. Tingkat sortian yang ada di PKS menjadi ancaman karena PKS masih memiliki standar yang cukup tinggi agar tidak mengurangi kualitas kegiatan produksi mereka.

2. Tingkat persaingan sesama satuan pemasok menjadi ancaman karena satuan pemasok sudah lebih dahulu memulai kegiatan pemasaran dibandingkan koperasi.

3. Resiko lamanya proses pemasaran produk TBS dapat mengurangi kualitas TBS yang akan dibawa ke PKS karena menurut Sukiran Ketua Pengurus koperasi, apabila mengalami antri lama dikhawatirkan kualitas TBS akan turun dalam waktu 2 hari setelah dipanen.

4. Resiko penolakan produk TBS oleh PKS yang masih sering terjadi dapat mengurangi keuntungan yang akan diperoleh koperasi.

5. Tinggi nya tingkat pertumbuhan satuan pemasok lain disekitar dikarenakan kawasan Aceh Tamiang ini merupakan kawasan perkebunan yang potensial untuk berbisnis dibidang perkebunan yang didukung juga oleh banyaknya PKS yang ada di Aceh Tamiang.

a. Pemberian bobot

Pemberian bobot dilakukan berdasarkan hasil dari pengisian kuisioner oleh petani yang tergabung dalam Koperasi Tani Bina Madani. Selanjutnya nilai bobot dari masingmasing indikator kekuatan dan faktor kelemahan (faktor internal) dijumlahkan maka akan berjumlah 22. Sedangkan nilai bobot faktor peluang dan faktor ancaman (faktor eksternal) dijumlahkan maka akan berjumlah 27,5. Nantinya data ini akan digunakan pada saat pencarian nilai bobot item.

b. Pemberian Bobot Item

Pemberian Bobot Item dilakukan dengan cara menjumlahkan terlebih dahulu kedua faktor Internal yaitu kekuatan dan kelemahan dan kedua faktor eksternal yaitu peluang dan ancaman. Dengan nilai faktor internal sebesar 22 dan faktor eksternal sebesar 27,5.

c. Pemberian Rating

Nilai rating diberikan dengan meminta bantuan narasumber kunci Ketua Pengurus Koperasi Tani Bina Madani Sukiran sebagai patokan. Ketua koperasi diharapkan mampu menjadi sumber yang paling mengerti kondisi koperasi baik dari internal maupun eksternal.

Selanjutnya setelah didapatkan Bobot Item dan juga Rating, tahap berikutnya ialah dengan mencari nilai Bobot Item x Rating yang dimana nantinya akan menjadi hasil untuk menentukan posisi Koperasi Tani Bina Madani di dalam diagram kartesius SWOT. 
Tabel 1. Faktor Strategi Internal Koperasi Tani Bina Madani

\begin{tabular}{llccc}
\hline No & Faktor-Faktor Strategi Internal & $\begin{array}{c}\text { Bobot } \\
\text { Item }\end{array}$ & Rating & $\begin{array}{c}\text { Bobot Item x } \\
\text { Rating }\end{array}$ \\
\hline Faktor kekuatan & & & \\
\hline 1 & Pengaruh lokasi koperasi dalam proses memasarkan & 0.159 & 4 & 0.636 \\
& TBS. & 0.141 & 3 & 0.424 \\
2 & Kualitas tenaga kerja yang ada di koperasi. & 0.144 & 4 & 0.578 \\
3 & Peran koperasi untuk petani di sekitarnya. & 0.153 & 4 & 0.610 \\
\hline & Sumber permodalan untuk koperasi. & & & $\mathbf{2 , 2 5}$ \\
\hline Total & 0.114 & 3 & 0.341 \\
\hline No & Faktor Kelemahan & 0.117 & 2 & 0.234 \\
2 & Keterbatasan ketersediaan TBS dari petani. & 0.078 & 1 & 0.078 \\
3 & Rendahnya kualitas TBS yang ditawarkan ke PKS. & & 0.188 \\
\hline & Keterbatasan jumlah petani yang bergabung dengan & & & \\
\hline & Keterbatasan jumlah karyawan koperasi. & & & $\mathbf{0 , 8 4}$ \\
\hline
\end{tabular}

Sumber: Data Primer Diolah (2017)

Total bobot item $\mathrm{x}$ rating pada Tabel 1 untuk faktor kekuatan bernilai 2,25 diperoleh dari penjumlahan bobot item $\mathrm{x}$ rating faktor kekuatan, dan total bobot item $\mathrm{x}$ rating untuk faktor kelemahan bernilai 0,84 diperoleh dari penjumlahan bobot item $\mathrm{x}$ rating faktor kelemahan yang nantinya digunakan sebagai acuan titik kondisi internal yaitu pada faktor kekuatan dan kelemahan pada Koperasi Tani Bina Madani.

Tabel 2. Faktor Strategi Eksternal Koperasi Tani Bina Madani

\begin{tabular}{|c|c|c|c|c|}
\hline No & Faktor-Faktor Strategi Eksternal & $\begin{array}{c}\text { Bobot } \\
\text { Item }\end{array}$ & Rating & $\begin{array}{l}\text { Bobot Item x } \\
\text { Rating }\end{array}$ \\
\hline & \multicolumn{4}{|l|}{ Faktor Peluang } \\
\hline 1 & Kemampuan menangkap pangsa pasar. & 0,125 & 3 & 0,374 \\
\hline 2 & Jalinan kerjasama koperasi dengan PKS. & 0,127 & 3 & 0,381 \\
\hline 3 & Citra koperasi yang baik dimata PKS. & 0,110 & 3 & 0,331 \\
\hline 4 & Tingkat daya beli PKS. & 0,125 & 4 & 0,498 \\
\hline \multirow[t]{2}{*}{5} & Permintaan pasar terhadap produk TBS koprasi. & 0,122 & 3 & 0,366 \\
\hline & Total & & & 1,95 \\
\hline No & \multicolumn{4}{|l|}{ Faktor Ancaman } \\
\hline 1 & Tingkat sortian yang ada di PKS. & 0,095 & 3 & 0,284 \\
\hline 2 & Tingkat persaingan sesama satuan pemasok. & 0,080 & 2 & 0,161 \\
\hline 3 & $\begin{array}{l}\text { Resiko lamanya proses pemasaran produk TBS dari } \\
\text { PKS. }\end{array}$ & 0,084 & 2 & 0,169 \\
\hline 4 & Resiko penolakan produk TBS oleh PKS. & 0,075 & 2 & 0,150 \\
\hline 5 & $\begin{array}{l}\text { Tinggi nya tingkat pertumbuhan satuan pemasok lain } \\
\text { disekitar. }\end{array}$ & 0,057 & 1 & 0,057 \\
\hline & Total & & & $\mathbf{0 , 8 2}$ \\
\hline
\end{tabular}

Sumber: Data Primer Diolah (2017) 
Total bobot item x rating pada Tabel 2 untuk faktor peluang bernilai 1,95 diperoleh dari penjumlahan bobot item $\mathrm{x}$ rating faktor peluang, dan total bobot item $\mathrm{x}$ rating untuk faktor ancaman bernilai 0,82 diperoleh dari penjumlahan bobot item $\mathrm{x}$ rating faktor ancaman yang nantinya digunakan sebagai acuan titik kondisi eksternal yaitu pada faktor peluang dan ancaman pada Koperasi Tani Bina Madani.

Selanjutnya nilai Bobot Item x Rating dari masing-masing indikator akan di kurangkan untuk mencari selisih dari setiap faktor Internal dan juga Eksternal. Maka diketahui nilai Kekuatan diatas dan nilai Kelemahan selisih (+) 1,41 dan nilai Peluang diatas nilai Ancaman selisih (+) 1,13. Dari hasil identifikasi faktor-faktor tersebut maka dapat digambarkan dalam Diagram SWOT pada Gambar 1 berikut:

Berbagai peluang $(1,95)$

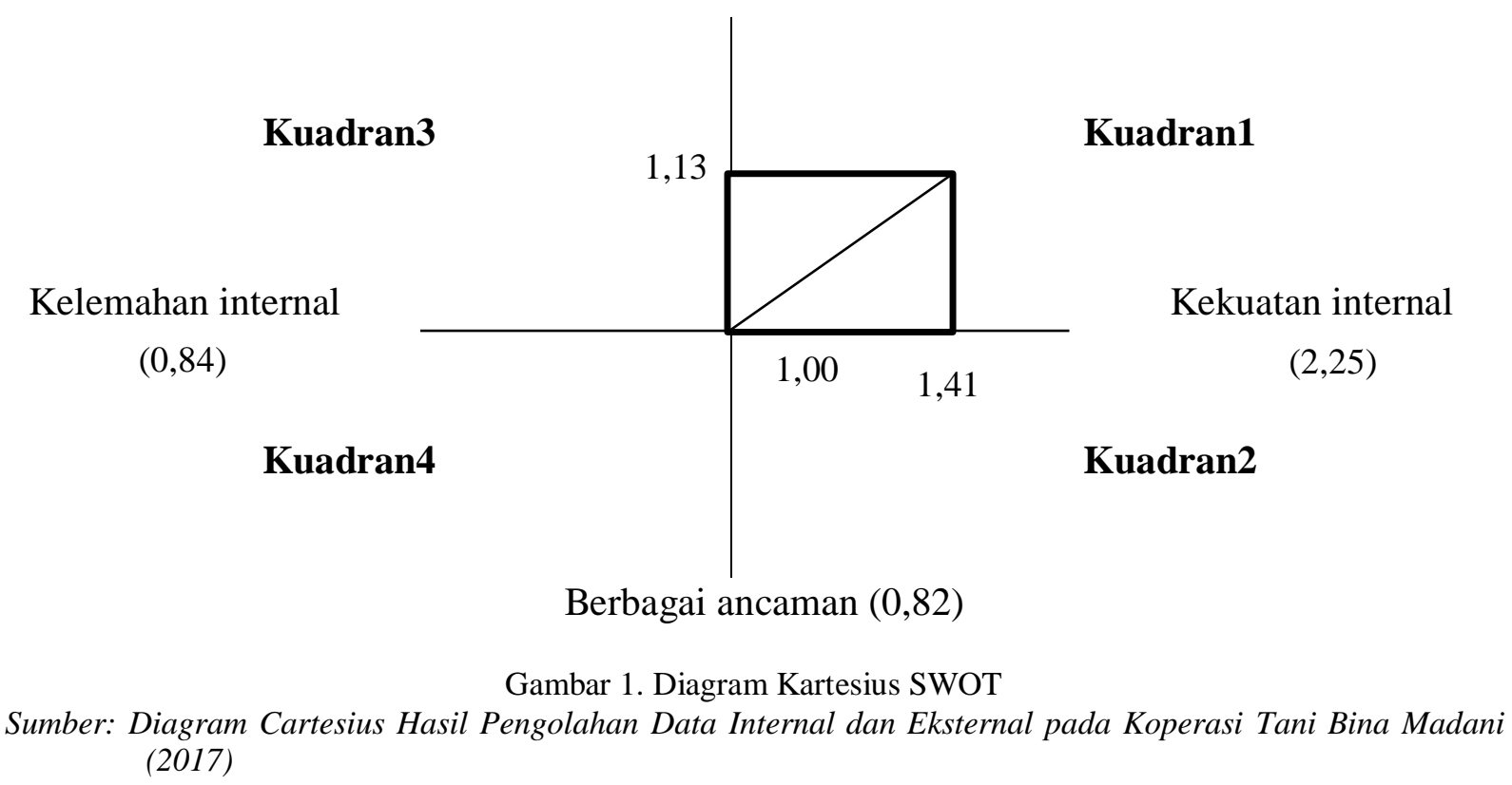

Dari hasil perhitungan di atas, di dalam perhitungan strateginya memerlukan penegasan dari adanya posisi yaitu antara kekuatan dan kelemahan, maupun peluang dan ancaman yang kesemuanya digambarkan dalam garis-garis positif dan negatif. Hal ini mengakibatkan, skor total kekuatan tetap 2,25, skor total kelemahan menjadi -0,84 sedangkan skor total peluang 1,95 , dan skor total ancaman menjadi $-0,82$.

Dari analisis tersebut di atas bahwa faktor kekuatan lebih besar dari faktor kelemahan dan pengaruh dari faktor peluang lebih besar dari faktor ancaman. Oleh karena itu posisi Koperasi Tani Bina Madani berada pada kuadran 1 yang berarti pada posisi pertumbuhan, dimana hal ini menunjukkan kondisi internal Koperasi Tani Bina Madani yang kuat, dengan lingkungan yang sedikit mengancam.

Posisi koperasi berdasarkan diagram kartesius berada pada posisi kuadran 1 yang menunjukkan pertumbuhan usaha. Pada kuadran 1 matrik internal-eksternal (IE) nilai internal Koperasi Tani Bina Madani memiliki nilai 3,09 dan nilai eksternal bernilai 2,77, yang dapat bahwa koperasi sudah memiliki kondisi internal yang memadai dan peluang yang ditawarkan juga sudah cuup memadai. Maka selanjutnya adalah penentuan dari identifikasi faktor internal dan eksternal dari koperasi untuk mendapatkan empat strategi utama dalam SWOT sebagai berikut: 
Tabel 3. Tabel Strategi SWOT.

\begin{tabular}{|c|c|c|}
\hline Faktor Internal & $\begin{array}{|ll|}\text { Kekuatan (S) } \\
\text { 1. } & \text { Respon dari PKS terhadap } \\
& \text { kualitas TBS koperasi } \\
& \text { yang ditawarkan. } \\
\text { 2. } & \text { Pengaruh lokasi koperasi. } \\
\text { 3. } & \text { Kualitas tenaga kerja. } \\
\text { 4. } & \text { Peran koperasi untuk } \\
\text { petani di sekitarnya. } \\
\text { 5. } & \text { Sumber permodalan untuk } \\
\text { koperasi. }\end{array}$ & $\begin{array}{l}\text { Kelemahan (W) } \\
\text { 1. } \text { Keterbatasan ketersediaan } \\
\text { TBS dari petani. } \\
\text { 2. } \text { Rendahnya kualitas TBS. } \\
\text { 3. } \\
\text { Keterbatasan jumlah petani } \\
\text { yang bergabung. } \\
\text { 4. } \\
\text { Keterbatasan } \\
\text { karyawan. }\end{array}$ \\
\hline \begin{tabular}{|ll|}
\multicolumn{2}{|l|}{ Peluang (O) } \\
1. & Kemampuan menangkap \\
& pangsa pasar. \\
2. & Jalinan kerjasama \\
& koperasi dengan PKS. \\
3. & Citra koperasi. \\
4. & Tingkat daya beli PKS. \\
5. & Permintaan pasar terhadap \\
& produk TBS. \\
\end{tabular} & \begin{tabular}{|l} 
Strategi (SO) \\
1. Menguatkan kerjasama \\
dengan pihak PKS dengan \\
mengusahakan kebijakan \\
yang menguntungkan \\
Koperasi dan seluruh mitra \\
serta anggota di dalamnya.
\end{tabular} & $\begin{array}{l}\text { Strategi (WO) } \\
\text { 1. Mengupayakan dukungan } \\
\text { sarana prasarana dari mitra } \\
\text { terkait serta membantu } \\
\text { petani secara langsung } \\
\text { untuk } \\
\text { kegiatan } \\
\text { nya. }\end{array}$ \\
\hline \begin{tabular}{|llr|}
\multicolumn{3}{|c|}{ Ancaman (T) } \\
1. & Tingkat sortian di PKS. \\
2. & Tingkat persaingan. \\
3. & Resiko lamanya proses \\
& pemasaran. \\
4. & Resiko penolakan TBS \\
& oleh PKS. \\
5. & Tinggi nya tingkat \\
& pertumbuhan \\
& pemasok lain.
\end{tabular} & \begin{tabular}{|l} 
Strategi (ST) \\
1. Melakukan sortiran awal \\
pada saat proses \\
pengambilan buah dari \\
petani untuk mengurangi \\
resiko ditolaknya buah dari \\
PKS.
\end{tabular} & $\begin{array}{l}\text { Strategi (WT) } \\
\text { 1. Menjaga hubungan dengan } \\
\text { petani anggota koperasi dan } \\
\text { juga berbagai pihak terkait. }\end{array}$ \\
\hline
\end{tabular}

Sumber: Data Primer Diolah (2017)

Berdasarkan keterangan pada tabel strategi SWOT tersebut, maka didapatkan empat strategi utama yang terdiri dari:

a. Strategi SO (strength dan opportunities ) Strategi ini dilakukan untuk memanfaatkan kekuatan perusahaan guna menangkap peluang yang dimiliki perusahaan.

b. Strategi ST (strength dan treats) Melakukan sortiran awal merupakan salah satu tindakan pencegahan awal agar buah yang dibawa ke PKS hanyalah buah yang sesuai dengan kriteria panen yang ada di PKS.

c. Strategi WO (weakness dan opportunities) Koperasi dapat mengupayakan adanya bantuan sarana dan prasaran yang datang dari pihak pemerintah, swasta yang berkaitan atau bahkan dari pihak koperasi sendiri.

d. Strategi WT (weakness dan treats) Disini yang dapat dilakukan koperasi ialah mempertahankan kualitas kinerjanya agar tidak menurun dan menghilangkan kepercayaan dari pihak terkait seperti petani anggota koeprasi dan juga pihak PKS.

Berdasarkan empat strategi pemasaran yang tepat untuk diterapkan pada Koperasi Tani Bina Madani tersebut, strategi yang sesuai dengan penentuan posisi koperasi dalam diagram 
SWOT untuk saat ini adalah menerapkan strategi SO (Strength Opportunities). Strategi SO (strength dan opportunities) ini dilakukan untuk memanfaatkan kekuatan koperasi guna menangkap peluang yang dimiliki koperasi. Menggunakan kerjasama dengan perusahaan terkait yaitu PT. Mopoli Raya akan dapat membantu meningkatkan penghasilan koperasi dalam memasarkan TBS. Kerjasama yang dapat dilakukan yaitu dengan membuat kebun petani yang tergabung didalam koperasi sebagai salah satu kebun afdeling dari perusahaan atau kebun afdeling desa.

\section{SIMPULAN DAN SARAN}

Adapun kesimpulan dari hasil penelitian ini adalah posisi koperasi dengan menggunakan analisis SWOT menunjukkan bahwa strategi pemasaran yang cocok diterapkan pada Koperasi Tani Bina Madani adalah dengan menggunakan strategi SO (Strength Opportunities). Jadi diharapkan dengan mengutamakan faktor kekuatan yaitu lokasi koperasi yang dekat dengan PKS serta juga peluang yang besar dari tingkat daya beli PKS yang tinggi maka diharapkan koperasi dapat mengusahakan kemitraan agar dapat menjadikan Kebun Rakyat yang tergabung di Koperasi Tani Bina Madani dapat menjadi bagian dari Afdeling PT. Mopoli Raya, seperti pada penelitian Tumimomor (2013) yang dimana Koperasi Bina Bersama berhasil membangun kemitraan dengan PT. Pola Kahuripan Intisawit namun masih terkendala sumber daya manusia yang belum ahli sehingga diharapkan untuk Koperasi Tani Bina Madani dapat mengusahakan kemitraan yang sejenis dengan adanya sumber daya manusia yang sudah merumpuni.

Adapun saran untuk Koperasi Tani Bina Madani, sebaiknya koperasi memfokuskan untuk mengusahakan kerjasama yang lebih baik seperti dengan melakukan kontrak awal untuk menjadikan Koperasi Tani Bina Madani sebagai salah satu pemasok TBS ke PKS, dan kerjasama untuk proses pemasaran kepada pihak PKS dengan kebijakan menjadikan kebun petani yang tergabung di koperasi sebagai kebun afdeling desa yang nantinya akan dapat membantu masyarakat sekitar dalam meningkatkan penghasilannya di bidang perkebunan kelapa sawit. Untuk pihak pemerintah diharapkan mempertimbangkan kembali kebijakan tentang Pajak Koperasi Perusahaan karena saat ini pajak tersebut masih sangat memberatkan pihak koperasi untuk meraih keuntungan sehingga secara tidak langsung dapat menurunkan keuntungan para petani anggota dari koperasi.

\section{DAFTAR PUSTAKA}

Agustira M.A., Amalia R, Nurkhoiry R. 2015. Program Sawit Untuk Rakyat (Prowitra) Sebagai Upaya Peningkatan Produktivitas, Pemberdayaan, Keberlanjutan, Dan Kesejahteraan Pekebun Kelapa Sawit Rakyat. Jurnal Pusat Penelitian Kelapa Sawit. 5: 315-324.

Alma, B.. 2008. Manajemen Pemasaran dan Pemasaran Jasa. CV. Alfabeta, Bandung.

Ariyantoro, H. 2006. Budidaya Tanaman Kehutanan. PT. Citra Aji Parama. Yogyakarta.

Assauri, S. 2013. Manajemen Pemasaran. Rajawali Pers, Jakarta.

Badrun, M. 2010. Tonggak Perubahan Melalui PIR Kelapa Sawit Membangun Negeri. Direktorat Jendral Perkebunan, Kementrian Pertanian Republik Indonesia, Jakarta. 
BPS Aceh Tamiang. 2015, Aceh Tamiang Dalam Angka, Aceh Tamiang.

Chandler, A.. 1962. Strategy and Structure: Chapters in The History of The industrial Enterprise. Cambridge Mass: MIT Press. London.

Departemen Pertanian, Direktorat Jenderal Perkebunan. 2014. Statistik perkebunan Indonesia 2013-2015: Kelapa Sawit (Oil Palm). Sekretariat Direktorat Jenderal Perkebunan, Jakarta.

Didu, M.S.. 2000. Rancangbangun Strategi Pengembangan Agroindustri Kelapa Sawit (Agrosawit). Jurnal Teknik Industri Pertanian. 11(1): 20-26.

Ikhsan, S. 2011. Analisis SWOT untuk Merumuskan Strategi Pengembangan Komoditas Karet di Kabupaten Pulang Pisau, Kalimantan Tengah. Jurnal Agribisnis Pedesaan. 01(3): 166-177.

Indriyo, G. 2000. Manajemen Pemasaran. Edisi II, BPFE, Yogyakarta.

Ketaren, S. 1986. Pengantar Teknologi Minyak dan Lemak Pangan. Edisi Pertama. UI-Press, Jakarta.

Kiswanto, Jamhari, H. P dan Bambang W. 2008. Teknologi Budidaya Kelapa Sawit. Balai Besar Pengkajian dan Pengembangan Teknologi Pertanian.

Kurniawan, A, C. 2004. Strategi Pengembangan Bisnis Kelapa Sawit (Studi Kasus Pada PTPN VIII, Propinsi Banten). Skripsi. Ilmu Sosial Ekonomi Pertanian, Fakultas Pertanian, ITB, Bogor.

Martodireso, S. dan Widada A.. 2001. Agribisnis Kemitraan Usaha Bersama. Kanisius. Jakarta

Nurmianto, E. 2004. Perumusan Strategi Kemitraan Menggunakan Metode AHP Dan SWOT (Studi Kasus Pada Kemitraan Pt. Inka Dengan Industri Kecil Menengah Di Wilayah Karesidenan Madiun). Jurnal Teknik Industri. 6(1): 47-60.

Pahan, I., 2006.. Kelapa Sawit, Upaya Peningkatan Produktifitas. Kanisius, Yogyakarta.

Rahardjo, S. \& Gudnanto. (2011). Pemahaman Individu Teknik Non Tes. Nora Media Enterprise, Kudus.

Rangkuti, F. 2009. Analisis Swot Teknik Membedah Kasus Bisnis. PT. Gramedia, Jakarta.

Sekaran, U.. 2011. Metode Penelitian Untuk Bisnis. Salemba Empat. Jakarta.

Setyawan, R.. 2015. Penerapan Analisis SWOT Sebagai Landasan Merumuskan Strategi Pemasaran Usaha Jasa Sewa Mobil "AMAN-AMIN" Transport Tours and Travel Ambarketawang Sleman Yogyakarta. Skripsi. Pendidikan Ekonomi. Fakultas Ekonomi. Universitas Negeri Yogyakarta. Yogyakarta. 
Sunarko. 2009. Budi Daya Dan Pengelolaan Kebun Kelapa Sawit dengan Sistem Kemitraan. Agromedia Pustaka. Jakarta.

Syaputra, D. Y.. 2015. Analisis Swot Usahatani Kelapa Sawit Di Desa Ulumahuam Ujung Padang A Kecamatan Silang Kitang Kabupaten Labuhan Batu Selatan Sumatera Utara. Skripsi. Departemen Ilmu Administrasi Niaga/Bisnis, Fakultas Sosial Dan Ilmu Poltik, Universitas Sumatera Utara, Medan.

Tumimomor, A. Y. S.. 2013. Pengelolaan Koperasi Dalam Program Kemitraan. Skripsi. Program Studi Ilmu Ekonomi, Fakultas Ekonomika dan Bisnis. Universitas Kristen Satya Wacana. Salatiga.

Wahyu R. E.. 2012. Faktor-Faktor Yang Mempengaruhi Pendapatan Dan Prospek Usahatani Kopi Rakyat Di Desa Sumberbulus Kecamatan Ledokombo Kabupaten Jember. JSEP. 6(3): 43-52.

Wahyudy, H. A.. 2015. Analisis Strategi Pengembangan Agribisnis Karet Rakyat Di Kabupaten Kuantan Singingi, Provinsi Riau. Junal Dinamika Pertanian. 30(3): 249-260. 